\title{
Importance of maternal history of non-insulin dependent diabetic patients
}

\author{
J C Alcolado, R Alcolado
}

\begin{abstract}
Objective-To assess the family history of diabetes in non-insulin dependent diabetes mellitus with particular emphasis on parental phenotype.

Design-Family histories were obtained from an existing computerised database and supplemented by postal questionnaires.

Setting-Diabetic service of a provincial teaching hospital.

Subjects-A total of 1326 patients with non-insulin dependent diabetes who had been referred to diabetic clinics over the past 10 years and from whom data had been collected for inclusion in the database, of whom 347 had affected first degree relatives. Nineteen non-white patients were excluded because of the differential hereditability of the disease, and $230(70 \%)$ patients with an affected first degree relative responded to the postal questionnaire.

Results - Mothers were implicated in significantly more cases than fathers in patients with a single affected parent: 125 mothers and 48 fathers from database; 82 mothers and 34 fathers from postal questionnaire; $\mathbf{p}<\mathbf{0 . 0 0 1}$ in both cases.

Conclusions - Maternal influences seem to have an important role in the inheritance of non-insulin dependent diabetes.
\end{abstract}

\section{Introduction}

The genetics of non-insulin dependent diabetes mellitus remains an enigma. It is well known that many patients give a positive family history, but attempts to place the disease into the simple mendelian pattern have failed. Furthermore, molecular genetic studies have not been as successful in finding disease markers as in insulin dependent diabetes. ${ }^{\prime}$ Several recent studies have suggested that intrauterine environment may also predispose to the development of non-insulin dependent diabetes. ${ }^{2}$ This would further complicate the transmission pattern of the disease by simulating genetic inheritance through maternal transmission. To clarify the genetics of non-insulin dependent diabetes and the role of maternal inheritance we studied the family history of a large number of patients with noninsulin dependent diabetes.

Medical Professorial Unit, St Bartholomew's Hospital, West Smithfield,

London EC1A 7BE

J C Alcolado, MRCP,

$R D$ Lawrence fellow of the

British Diabetic Association

Medical Professorial Unit, Southampton General

Hospital, Southampton

R Alcolado, BM, registrar

Correspondence to:

Dr J C Alcolado.

BMF 1991;302:1178-80

\section{Patients and methods}

Many diabetic patients in the Cambridge area are referred to hospital based specialist clinics. After initial assessment the patients either continue to attend hospital clinics or are seen in diabetic "mini clinics" run by general practitioners. All diabetic patients seen at any time in a hospital clinic have clinical data recorded on standardised forms and subsequently entered into a computerised database, primarily for audit purposes. Details of diagnostic criteria, complications, treatment, and family history have been entered into the database over the past 10 years. Patients' details are entered into the database regardless of family history or any other confounding criteria. Family history data were entered "blind" in that no person connected with the present study was involved in either collecting data or entering them into the computer.

The database resource was searched for all noninsulin dependent diabetes patients with documented first degree affected relatives. Details were thus obtained of the overall prevalence of affected relatives in the study population. The number and type (mother, father, brother, or sister) of relatives affected were noted for each patient. Postal questionnaires were sent to all index patients at their last known address to assess the reliability of the computerised data. The questionnaire requested details of affected first degree relatives including name, age, approximate duration of disease, and treatment (diet, oral hypoglycaemic agents, or insulin). Additional information obtained included age at death of mothers and fathers and the total number of siblings, affected and unaffected, within the family.

\section{Results}

Details were available from a total of 1326 patients with non-insulin dependent diabetes, of whom 347 (26\%) had affected first degree relatives. In view of the differential hereditability of the disease in racial groups, 19 non-white index patients with a positive family history were not considered further.

Completed postal questionnaires were received from 230 of the 328 white index patients (70\%). A further 10 questionnaires were returned stating that index patients had either died or moved away from the area. The names of affected first degree relatives listed on posta responses were checked against those already in the database to exclude related patients, whose presence would bias results. A total of four related index patients were identified from the 230 postal returns and excluded from the study.

Details of patients in this study are given in table I.

TABLE I-Details of patients with affected first degree relatives entered into study

\begin{tabular}{lcc}
\hline & \multicolumn{2}{c}{ Source of information } \\
\cline { 2 - 3 } & $\begin{array}{c}\text { Database } \\
(\mathbf{n}=325)\end{array}$ & $\begin{array}{c}\text { Postal questionnaire } \\
(\mathbf{n}=230)\end{array}$ \\
\hline Sex (No (\%) women) & $172(53)$ & $131(57)$ \\
Mean (range) age (years) & $66(36-96)$ & $65(36-89)$ \\
Mean (range) duration of disease & Not available & $8(1-25)$ \\
\hline
\end{tabular}

From the information in the database, parents were implicated in $183(56 \%)$ of 324 index patients with an affected first degree relative; 125 had an affected mother, 48 had an affected father, and 10 had both. From the postal questionnaire, 122 cases implicated parents: 82 mothers and 34 fathers, and in a further six cases both parents were affected (table II).

Postal respondents gave details of the parents' age at diagnosis of diabetes and their approximate age at death. The mean age at death of mothers was 73 years and that of fathers 69 years. There was no significant difference between the age at death of mothers or fathers. Offspring recalled that both mothers and fathers had become affected with the disease most 
TABLE II-Parental history of non-insulin dependent diabetes among index patients

\begin{tabular}{lcc}
\hline & \multicolumn{2}{c}{ Source of information } \\
\cline { 2 - 3 } & Database & Postal questionnaire \\
\hline Father alone & 41 & 27 \\
Father plus 1 sibling & 5 & 7 \\
Father plus 2 siblings & 2 & 0 \\
Father plus 3 or more siblings & 0 & 0 \\
Mother alone & 86 & 46 \\
Mother plus 1 sibling & 22 & 23 \\
Mother plus 2 siblings & 11 & 6 \\
Mother plus 3 or more siblings & 7 & 7 \\
Mother and father & 10 & 6 \\
\hline
\end{tabular}

TABLE III-Diabetic state of siblings of index patients ( $f 1$ generation: all subjects in same generation as index patients)

\begin{tabular}{lrrr}
\hline & Men & Women & Total \\
\hline All siblings & 417 & 409 & 826 \\
Affected siblings & 120 & 106 & 226 \\
$\begin{array}{c}\text { Total No of members of generation (all siblings } \\
\text { plus index patient) }\end{array}$ & 515 & 535 & 1050 \\
$\begin{array}{c}\text { Total No of affected members in generation } \\
\text { (affected siblings plus index patient) }\end{array}$ & 218 & 232 & 480 \\
\hline
\end{tabular}

often in the fifth decade of life (range third to eighth decades).

Information concerning the current diabetic state of siblings of postal respondents is shown in table III. Among the postal respondents, the mean number of offspring of diabetic mothers was five (range 1-13). The mean number of offspring of diabetic fathers (that is, in the group that represents non-diabetic mothers) was also five. From these data we conclude that parity did not seem to influence the development of diabetes in mothers within this population.

In the statistical analysis the null hypothesis tested was that mothers and fathers have an equal chance of transmitting the genetic predisposition to diabetes to their offspring. Slightly more women index patients were registered on the database: $53 \%$ (SE 3\%) of patients were female, and this was similar in the replies to the postal questionnaire $(57 \%(3 \%)$ female) From analysis of the postal replies, the 220 families represented had a total of 1050 members in the first filial (f1) generation (all subjects in the same generation as the index patients) (table III). Of these, $515(49 \%)$ were men, and $450(43 \%)$ people in the $\mathrm{fl}$ generation had diabetes at the time of the study, of whom 230 (51\%; SE 2\%) were women. From the data obtained we concluded that there may be a small female preponderance of non-insulin dependent diabetes in the study population, and this was taken into account when considering the significance of maternal versus paternal influences.

From the database, in the 173 families with a single diabetic parent there were 125 affected mothers and 48 affected fathers. If there were no female preponderance in the diabetic population and the null hypothesis were correct then equal numbers of affected mothers and fathers ( 87 of each) would be expected. Taking a female preponderance of $53 \%$, if the null hypothesis is correct then 92 mothers and 81 fathers would be affected. The expected values, taking into account the probable female preponderance, versus the observed values were analysed by the $\chi^{2}$ test $\left(\chi^{2}=25 \cdot 2, \mathrm{df}=1\right.$, $\mathrm{p}<0.001)$. A similar calculation with the results from the postal questionnaire yielded $\chi^{2}=16 \cdot 8, p<0 \cdot 001$.

\section{Discussion}

This study relies on information from a diabetic service's computer database and postal questionnaires. The only selection criterion for the study group, therefore, was having been seen at a hospital based diabetic clinic; this should not result in bias of the parental history. Kahn et al have reported that patients with non-insulin dependent diabetes give an accurate family history when questioned carefully, ${ }^{3}$ and therefore the data presented are likely to be a good reflection of the true diabetic state of first degree relatives.

The postal questionnaire was used to validate the database information and to gain further clinical details. Of prime importance was the exclusion of related patients from the database as this could bias the analysis. Postal respondents gave the names of affected relatives, and this resulted in the exclusion of four index patients from the database analysis, of whom one had an affected mother and one had an affected father. Among the 95 non-respondents 43 had database documentation of affected mothers and 14 had database documentation of affected fathers. Of these 57 cases, only those with an affected parent and siblings could alter our analysis and then only if the affected sib was already present in the database. None of these non-respondents had the same surname. Only two out of 220 replies required exclusion of parental disease from the database analysis; consequently it is unlikely that the 57 non-respondents who had an affected parent would lead to many index patients being excluded.

The postal and database family histories agreed in 171 of the 220 families. In a further 26 cases the parental history was vindicated but the number of affected siblings was incorrect. In 18 of these cases a greater number of affected siblings was listed on the postal replies, and this may be due to the development of disease in relatives since the initial collection of information for the database. In only nine out of the 230 respondents $(4 \%)$ was the parental history obtained from the database different from that obtained from the questionnaire.

This study confirms the high hereditability of noninsulin dependent diabetes. As in other studies, ${ }^{4}$ our results show a slight excess of women $(53 \%)$ in the index group. Current opinion suggests that susceptibility to non-insulin dependent diabetes may be the result of inheritance of a small number of autosomally transmitted gene variants. ${ }^{5}$ If this were the case equal numbers of affected mothers and fathers would be expected, but our study shows a large and significant overrepresentation of mothers, even taking into account the small excess of women index patients.

In the United Kingdom women on average live longer than men. ${ }^{6}$ This could explain some of the maternal preponderance observed, especially if fathers died before middle age, when non-insulin dependent diabetes tends to be diagnosed. However, in this population our study shows no significant difference between the mean age at death of fathers and mothers nor the mean age at onset of the disease in affected parents.

Another explanation for our results is that offspring of diabetic mothers develop the disease earlier than those of diabetic fathers and are therefore overrepresented in the hospital diabetic population. This hypothesis is not supported by the data from the postal responses, which showed that the mean age at onset of diabetes in index patients with affected mothers or fathers was 57 years (range 30-88 years) in both cases. To test this hypothesis more rigorously a long term prospective study is required.

True genetic maternal autosomal inheritance may result if maternally derived genes are passed on to offspring in preference to paternal genes (such as in the mitochondrial myopathies $)^{7}$ or if maternal genes are preferentially switched on during ontogeny.

Recent studies suggest that intrauterine environment may have a role in the transmission of non-insulin dependent diabetes. Offspring of Pima Indian women are more likely to develop diabetes if their mothers 
were diabetic during the pregnancy than if the mothers developed diabetes later in life. ${ }^{2}$ Thus intrauterine factors can result in a preponderance of affected mothers over fathers without implicating mendelian mechanisms. In the present study, data are not available on the diabetic state of mothers at the time of pregnancy. A long term prospective population study would be required to obtain these data with certainty, following up the offspring for the development of diabetes. Such studies are more readily performed in populations, such as the Pima Indians, in which the prevalence of diabetes is large and the age of onset is relatively low. In the United Kingdom such a study would take over 50 years to complete. The prospective study of non-insulin dependent diabetes currently under way in Ely, Cambridgeshire, may eventually provide some answers.
We thank Dr O M Edwards and Miss N Challinor for use of the Cambridge diabetic service database. Drs M G Baroni, S R Li, J Thorn, and J Stocks provided useful suggestions.

1 O'Rahilly S, Wainscoat J, Turner R. Type 2 (non-insulin dependent) diabetes mellitus. New genetics for old nightmares. Diabetologia 1988;31:407-14.

2 Pettit D, Aleck K, Baird R, Carracher M, Bennett P, Knowler W. Congenital ettit D, Aleck K, Baird R, Carracher M, Bennett P, Knowler W. Congenital susceptibility

3 Kahn LB, Marshall JA, Baxter J, Shetterly SM, Hamman RF. Accuracy of reported family history of diabetes mellitus: results from San Luis Valley reported family history of diabetes melli

4 Mohan V, Sharp P, Aber V, Mather H, Kohner E. Family histories in Asian and Mohan V, Sharp P, Aber V, Mather H, Kohner E. Family histo
European diabetic patients. Practical Diabetes 1986;3:254-6.

5 Bell GI, Xiang K, Horita S, Sanz N, Karam JH. The molecular genetics of diabetes mellitus. Ciba Found Symp 1987;130:167-83.

6 Office of Population Censuses and Surveys. Census 1981. National report, Great Britain. London: HMSO, 1983.

7 Harding AE, Petty RKH, Morgan-Hughes JA. Mitochondrial myopathy: a genetic study of 71 cases. $\mathcal{F}$ Med Genet 1988;25:528-35.

(Accepted 4 April 1991)



\title{
Home nebulisers in childhood asthma: survey of hospital supervised use
}

\author{
Ilona $M$ Bendefy
}

\begin{abstract}
Objective-To review the management of and outcome in asthmatic children using home nebulisers under hospital supervision.

Design-Postal questionnaires sent to parents.

Setting-Paediatric departments of a children's hospital and a district general hospital.

Subjects-Parents of 93 asthmatic children who had been loaned home nebulisers for administration of bronchodilators with verbal instructions on their use.

Main outcome measures-Drugs administered with nebuliser, side effects, frequency of hospital admission, and theoretical management of a severe attack.

Results -84 children took salbutamol and 37 received more than $10 \mathrm{mg}$ a day during attacks; side effects were reported in 54 children. Parents of $\mathbf{1 6}$ children said that they would give another dose of bronchodilator rather than seek medical help if their child failed to respond to the first dose. Since being loaned nebulisers 65 children were admitted to hospital less frequently and 16 were not readmitted; over two thirds of parents thought that there had been a marked improvement in their child's asthma.

Conclusions-Home nebulisers are valuable in childhood asthma. Excessive doses of bronchodilators may be given, however, and a weight related dose may be more appropriate. Parents should be given written as well as verbal instructions, especially regarding the management of severe attacks.
\end{abstract}

\section{Introduction}

Nebulisers are the most effective way of administering bronchodilators during an acute asthma attack. ${ }^{1}$

Department of Community Child Health, Community House, Morden, Surrey Ilona M Bendefy, MRCP, paediatric registrar

Correspondence and requests for reprints to Dr Ilona M Bendefy, 28 Brodrick Road, London SW17 7DY.

BMF 1991;302:1180-1 asthma. ${ }^{45} \mathrm{~A}$ district hospital survey of asthmatic patients using home nebulisers in Britain, including 22 children under 7 years, showed confusion among patients about when and how to use the nebuliser, a lack of hospital supervision, and excessive use of bronchodilators in some patients.

I reviewed the management of asthma and outcome in a group of children using home nebulisers under hospital supervision, paying particular attention to dose of bronchodilator, prevalence of side effects, and the parents' understanding of how to manage a severe asthma attack.

\section{Subjects and methods}

I studied asthmatic children who received regular medical supervision from a district general hospital or a nearby children's hospital. The decision to lend children a home nebuliser was made by the consultant in each case. The loan and yearly servicing of the nebulisers was arranged by the community nursing service based at the children's hospital. The nurses verbally instructed each family on the use and maintenance of the nebuliser. Parents were told never to exceed the prescribed dose, never to give the dose more often than four hourly, and to seek medical advice or bring the child to hospital if there was no improvement after the first dose of bronchodilator. Parents were not routinely given written instructions, although 12 parents were given individual written guidelines.

\section{Results}

One hundred and twelve children were using home nebulisers, and the parents of 107 (96\%) completed a postal questionnaire (box). Ninety three children were using nebulisers to take bronchodilators.

The children were aged from $1 \cdot 2$ to $14 \cdot 7$ (median $4 \cdot 7)$ years, and the male to female ratio was $2: 1$. They had used home nebulisers for 0.2 to $8 \cdot 7(1.6)$ years. All but four children had been admitted to hospital with asthma at least once before being loaned a nebuliser. The two most common nebulisers used were the PortaNeb 20 (40 children) and the Porta-Neb Multivolt (37 children), both made by Medic-Aid, Chichester. Eighty four children took salbutamol, six ipratropium bromide, and three terbutaline through the nebuliser. 